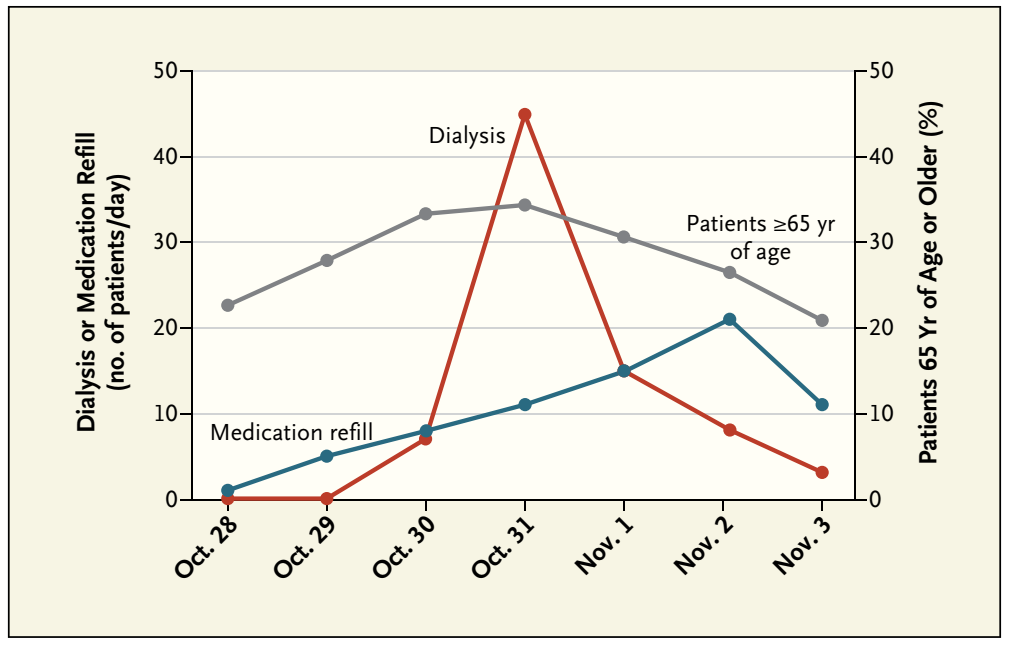

Distribution of Patients in Beth Israel's Emergency Department after Hurricane Sandy.

network." Since the Wi-Fi was still working, residents downloaded a telephony app onto their phones and used it to send urgent text messages. At one point, the system brought several residents together for a code in a dark room. By the glow of headlamps and bobbing flashlights, a resident began resuscitation while others prepared to place a central catheter. While Samad tried to sustain morale, dutyhour limits were no longer top priority - though the influx of outpatient providers helped residents get some rest. Like the boundaries defining a resident, a medicine ward attending, a housekeeper, a surgeon, and a social worker, the lines defining work shifts had blurred.
Nagler recalls that when he first became Beth Israel's president, he "got on the subway one morning and was thrust against the front of the subway car, pushed against the window by the crowd, and the view in front of me was pitch black except for the gleam of the tracks." He remembers this image every time he faces the unexpected, hopeful he will find a path forward. When I visited the hospital 5 days after Sandy, the lights were back on, but in a sense Nagler still felt like he was on that subway, hurtling toward an uncertain destination. Many nearby hospitals remain closed, and high volumes continue. And even after this crisis ends, another unpredictable event is bound to occur, and whether it's a hurricane, a terrorist attack, or an infectious disease outbreak, it will pose its own obstacles.

As Manhattan works to repair itself, local clinicians find that part of their job is to evolve under duress, trying to provide good care under dynamic circumstances. One NYU hospitalist, lacking patients in her own hospital, visits evacuated patients at their new facilities, bridging gaps in the medical record. She is navigating a foreign landscape, but most health care professionals will encounter such unfamiliar terrain sometime during their careers.

Nagler returns to his musing on meteorology. The weather and medicine are similar in many ways, he remarks, both full of complex variables that produce unpredictable outcomes. But the hospital managed to meet such outcomes with creative and rapid solutions. Nagler looks out the window onto 16th Street. The sun has emerged, briefly, over Manhattan, and somewhere nearby an ambulance siren wails.

Disclosure forms provided by the author are available with the full text of this article at NEJM.org.

Dr. Jangi is an editorial fellow at the Journal and a hospitalist at Beth Israel Deaconess Medical Center in Boston.

This article was published on November 14 , 2012, at NEJM.org.

DOI: 10.1056/NEJMp1213844

Copyright @ 2012 Massachusetts Medical Society.

\title{
Lessons from Sandy - Preparing Health Systems for Future Disasters
}

Irwin Redlener, M.D., and Michael J. Reilly, Dr.P.H., M.P.H.

WTithin hours after Hurricane

Sandy's landfall, doctors and staff at one of New York City's premier medical centers realized that something was go- ing terribly wrong. Lights were flickering, critical devices essential to life support for more than 200 patients, many in intensive care units, were malfunctioning.
A decision had to be made by hospital leaders, senior public health officials, and emergency responders: tough it out in a hospital without power or attempt a perilous 


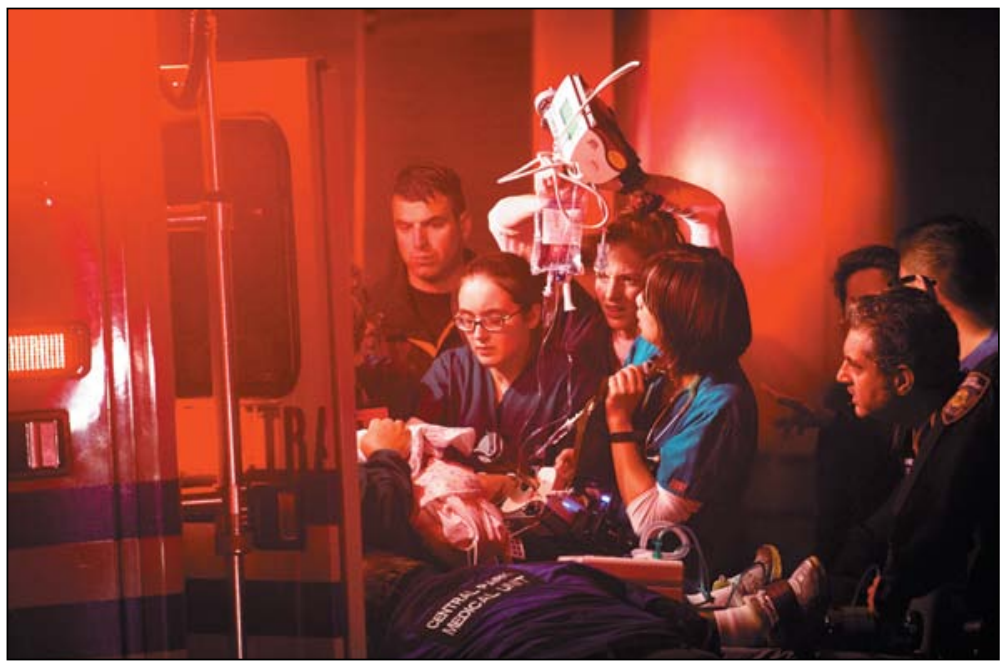

patient evacuation as an epic disaster unfolded.

With little time to lose, the "go" order was given, followed by frantic calls to high-ground hospitals identifying beds for receiving New York University-Langone Medical Center's critically ill patients. St. Luke's-Roosevelt, Mt. Sinai, New York Presbyterian at Columbia, and many other hospitals responded immediately, opening beds, readying emergency admission procedures, and briefing staff.

Two days later, the story was repeated. Bellevue Hospital, which had been operating without sufficient power and with failing generator fuel pumps, was also evacuated, sending more than 700 patients to other facilities around the city.

The NYU hospitals' stories were extraordinary. Doctors, nurses, support staff, first responders, and National Guard troops rose to the occasion, with bucket brigades transporting fuel to generators on high floors and slowly, carefully maneuvering fragile patients down dark stairways into the storm, where ambulances were waiting to move patients to the receiving hospitals. ${ }^{1}$ That all this took place without loss of life or immediately apparent medical consequences was remarkable.

But questions about why these extreme measures were necessary will have to be answered in the months ahead. Although the first question may be how to prevent power failure, the nuances of backup and redundant power generation are not generally within the expertise of health professionals. And in fact, the generators themselves were probably fine; the problem appears to have been that fuel pumps supplying the generators were in the basement, highly susceptible to breakdown from flooding. ${ }^{1}$ Ways of ensuring resiliency of backup power equipment will certainly be investigated later. For now, it's important to understand what medical and public health challenges are to be expected after megadisasters such as Hurricane Sandy.

The first order of business is always to identify and treat stormrelated casualties requiring urgent attention. ${ }^{2}$ Initial reports indicate that emergency care systems in New York and most of the affected region functioned well during and immediately after the storm. However, when major medical centers are incapacitated, the stress on remain- ing facilities may be extreme. Accommodations must be made for both a disaster-related surge in patients and the usual intake of patients with unrelated urgent medical and surgical needs.

Second, potentially serious public health complications may follow large-scale storms with extensive flooding. Though not inevitable, the possibility of the rapid emergence of such secondary public health threats demands sophisticated surveillance. Dangerous debris can clog streets and pose serious hazards to pedestrians. Breakdowns or overflows in sewer systems and watertreatment plants can result in contaminated drinking water and waterways. Toxic wastes and miscellaneous carcinogens from Superfund sites can spread over wide areas, exposing storm survivors to latent dangers.

In fact, overflow from the toxin-filled Gowanus Canal in Brooklyn is already a concern that will require close monitoring. ${ }^{3}$ Prolonged lack of power and heat, a real problem in the first 2 weeks after Sandy, became dangerous for the elderly, homebound patients, and small children, especially those living in low-income housing projects. There are already signs of dangerous mold infestations in dwellings soaked by rain and floods. Also, more injuries are expected in the weeks after such disasters, as homeowners attempt to repair houses or property.

Third, essential supply chains must be restored. The most obvious and critical concern is ensuring that patients receiving life-critical medications or supplies have uninterrupted access. ${ }^{4}$ Visits to shelters in the region revealed that many people lacked backup medication supplies or prescriptions. Patients - and 
shelter managers - often had little information about how or where to obtain these necessities. Then fuel shortages plagued storm-ravaged communities as gas stations lost power and the fuel supply chain was disrupted. Anecdotal reports of problems obtaining food and water were widespread. As a result, medically vulnerable patients have been at heightened risk, though quantifying the consequences of these shortages is challenging.

Finally, access to health care, often a casualty of large-scale disasters, has been a major challenge in Sandy's aftermath. Offices, clinics, and hospitals were damaged, some irreparably. Some health care providers leave the community before or after such events, at least temporarily. For hundreds of thousands of people who have inadequate access in the best of times, some of whom have serious chronic conditions, disasters greatly exacerbate problems in receiving comprehensive or timely care. Mental health problems are a common consequence of disasters. Loss or injury of loved ones, highly disrupted neighborhoods, and severely damaged property represent extreme stressors for many people and pose even greater risk for children and for people with preexisting psychological or behavioral problems. Most regions have serious shortages of resources for addressing such problems.

We have moved beyond immediate response to Hurricane Sandy into an early recovery phase. But new challenges will be added to the to-do list for a highly stressed health care system. Long-term shelters will be established, and displaced persons may be housed far away from their original communities, placing further demands on local hospitals and providers. Many resources initially provided by neighboring states and the federal government will be withdrawn, though we hope that some elements of the hospital system that were shut down by the storm will be back in service.

As we move forward, some key principles should be kept in mind. It's essential, for instance, to consider the health care delivery system and the public health infrastructure as an integrated whole in planning for, responding to, or recovering from large-scale disasters. And details matter. Safe placement of backup electrical generators is insufficient if resiliency of fuel supply is inadequate. A reliable system whereby ambulatory patients can sustain their medication supplies may save lives. Knowing where homebound, frail persons are located can make it possible for responders to check on health status and supplies of food and water.

We must also do better in applying lessons from previous disasters to the planning for future events. The analysis of the aftermath of Hurricane Katrina and the flooding of New Orleans warned planners about virtually all the health system problems that we've faced in the aftermath of Hurricane Sandy.

Although experience is a great teacher, science can and should also inform disaster policy. Too often it does not. Careful tracking of important health and mental health problems that confound recovery, for instance, may lead to appropriate interventions that can help reduce morbidity associated with the inevitable next catastrophe.
Finally, two key realities make us more vulnerable to future disasters. Critical infrastructure, from levees to the electrical grid, is aging and increasingly fragile, ever more subject to breakdown with massive consequences for human health and safety. ${ }^{5}$ And many scientists are convinced that climate change, with resultant changes in sea level and weather patterns, will make more frequent and severe storms a grim reality in the years ahead. Since these two powerful factors represent imminent threats to the public health, it's fair to ask what role our profession will play in influencing the political process to ensure that we invest in upgrading critical infrastructure and implement policies that will slow the process of climate change.

Disclosure forms provided by the authors are available with the full text of this article at NEJM.org.

From the National Center for Disaster Preparedness, Mailman School of Public Health, Columbia University, New York.

This article was published on November 21, 2012, at NEJM.org.

1. Hartocollis A, Bernstein N. At Bellevue, a desperate fight to ensure the patients' safety. New York Times. November 2, 2012: Al (http://www.nytimes.com/2012/11/02/ nyregion/at-bellevue-a-desperate-fight-toensure-the-patients-safety.html?pagewanted $=$ all\&_$r=0$ ).

2. Clements BW. Disasters and public health: planning and response. Burlington, MA: Butterworth-Heinemann, 2009.

3. U.S. Environmental Protection Agency. Gowanus Canal: Hurricane Sandy sampling results. November 10, 2012 (http://www .epa.gov/region2/superfund/npl/gowanus). 4. Hupert N, Muckstadt JA, Xiong W. Quantitative planning for epidemic and disaster response: logistics and supply chain considerations. In: Reilly MJ, Markenson DS, eds. Health care emergency management: principles and practice. Sudbury, MA: Jones and Bartlett Publishers, 2011:223-32.

5. Redlener I. Americans at risk. New York: Knopf, 2006.

DOI: 10.1056/NEJMp1213486

Copyright $\odot 2012$ Massachusetts Medical Society. 